\title{
Implementasi Kebijakan Kawasan Tanpa Rokok di Rumah Sakit Umum Daerah (RSUD) UNDATA-Palu
}

\section{Implementation of the Non-Smoking Area Policy at the UNDATA-Palu Regional General Hospital}

\author{
${ }^{1}$ Sadry Budiwan, ${ }^{2}$ Arwan, ${ }^{3}$ Sadli Syam \\ ${ }^{1}$ Jurusan Administrasi dan Kebijakan Kesehatan, Fakultas Kesehatan Masyarakat, Universitas Tadulako, Palu, Indonesia \\ 2,3 Jurusan Promosi Kesehatan, Fakultas Kesehatan Masyarakat, Universitas Tadulako, Palu, Indonesia
}

\begin{tabular}{|c|}
\hline A RTICLE INFO \\
\hline $\begin{array}{l}\text { Article history : } \\
\text { Received 2021-June-09 } \\
\text { Received in revised form 2021-Jur } \\
\text { Accepted 2021-June-16 }\end{array}$ \\
\hline $\begin{array}{l}\text { Keywords : } \\
\text { Policy Implementation } \\
\text { Non-Smoking Area } \\
\text { Hospital }\end{array}$ \\
\hline $\begin{array}{l}\text { Kata Kunci : } \\
\text { Implementasi Kebijakan } \\
\text { Kawasan Tanpa Rokok } \\
\text { Rumah Sakit }\end{array}$ \\
\hline $\begin{array}{l}\text { Correspondence : } \\
\text { Sadry Budiwan } \\
\text { Email : sadrysykes@gmail.com. }\end{array}$ \\
\hline
\end{tabular}

\begin{abstract}
A B S T R A C T
RSUD UNDATA Palu is a health service facility that should have $100 \%$ to implement the area without cigarettes but until now there are still visitors who do the activity of smoking in the corridor even in the hospital room. Based on Palu City Regulation No. 3 of 2015 on non-smoking areas that are not allowed to engage in smoking activities in areas that have been designated as non-smoking areas, including in health care facilities. The purpose of this study is to know the concept of communication, resources, disposition and bureaucratic structure in the Implementation of Regional Regulation of Palu City No. 3 of 2015 about non-smoking areas in RSUD UNDATA Palu. The research method used is qualitative research with case study approach. The result is that the concept of communication is good enough. KTR Task Force in RSUD UNDATA uses printed and electronic media. In the variable resources obtained results that are not good enough. The KTR taskforce at RSUD UNDATA is still less than the number that there are only 15 people who previously amounted to 30 people. In the disposition variable obtained in this study is good enough. The appointment of the KTR taskforce at UNDATA Hospital was directly elected by the hospital director, but the supervisory officers still lacked incentives. In the variable of bureaucracy structure got good result. The most authorized in implementing implementation of KTR policy implementation in RSUD UNDATA Palu is coordinator of task force. Suggestions in this research KTR Task Force in RSUD UNDATA should be added plus and the RSUD UNDATA to make smooking area.
\end{abstract}

\begin{abstract}
A B S T R A K
RSUD UNDATA Palu merupakan fasilitas pelayanan kesehatan yang seharusnya sudah $100 \%$ menerapkan kawasan tanpa rokok tapi sampai dengan saat ini masih terdapat pengunjung yang melakukan aktivitas merokok di koridor bahkan dalam ruangan rumah sakit. Berdasarkan Peraturan Daerah Kota Palu Nomor 3 Tahun 2015 tentang kawasan bebas rokok bahwa tidak di perbolehkan melakukan aktivitas merokok pada wilayah yang sudah ditetapkan sebagai kawasan tanpa rokok termasuk di fasilitas pelayanan kesehatan. Tujuan penelitian ini untuk mengetahui konsep komunikasi, sumber daya, disposisi dan struktur birokrasi dalam Implementasi Peraturan Daerah Kota Palu Nomor 3. Tahun 2015 tentang kawasan bebas rokok di RSUD UNDATA Palu. Metode penelitian yang digunakan adalah penelitian kualitatif dengan pendekatan studi kasus. Didapatkan hasil bahwa konsep komunikasi sudah cukup baik. Satgas KTR di RSUD UNDATA menggunakan media cetak dan elektronik. Pada variable sumber daya didapatkan hasil yang tidak cukup baik. Satgas KTR di RSUD UNDATA masih kurang dari sisi jumlah yaitu hanya terdapat 15 orang yang sebelumnya berjumlah 30 orang. Pada variable disposisi yang didapatkan dalam penelitian ini sudah cukup baik. Pengangkatan satgas KTR di RSUD UNDATA dipilih secara langsung oleh direktur rumah sakit, akan tetapi petugas pengawas masih kekurangan insentif. Pada variable struktur birokrasi didapatkan hasil cukup baik. Yang paling berwenang dalam pelaksanaan implementasi pelaksanaan implementasi kebijakan KTR di RSUD UNDATA Palu adalah koordinator satgas. Saran dalam penelitian ini Satgas KTR di RSUD UNDATA sebaiknya ditambah ditambah dan pihak RSUD UNDATA agar membuat smooking area.
\end{abstract}

\section{PENDAHULUAN}

Rokok merupakan salah satu penyumbang terbesar penyebab kematian yang sulit dicegah dalam masyarakat. Kandungan senyawa penyusun rokok yang dapat mempengaruhi pemakai adalah golongan alkaloid yang bersifat perangsang (stimulant), antara lain: nikotin, nikotirin, anabasin, myosmin. Kebiasaan merokok yang bersifat adiktif dapat menyebabkan terbentuknya sifat egois dari para perokok, hal ini dapat terlihat dari kebiasaan merokok di depan umum dan di tempat-tempat terbuka (fasilitas umum) (1).

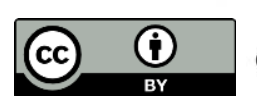


Penggunaan rokok merupakan salah satu faktor risiko terbesar pada penyakit tidak menular dan penyakit menular, karena itulah kebijakan menerapkan kawasan tanpa rokok (KTR) telah diidentifikasi sebagai strategi intervensi utama dalam pengendalian penyakit dan penyehatan lingkungan. Untuk mengatasi itu, maka Kementerian Kesehatan Republik Indonesia mengharapkan para Gubernur segera mengeluarkan kebijakan tentang Kawasan Tanpa Rokok di wilayah kerja masing-masing sesuai dengan Peraturan Bersama Menteri Kesehatan dan Menteri Dalam Negeri Nomor 188/MENKES/PB/I/2011 dan Nomor 7 Tahun 2011 tentang Pedoman Pelaksanaan Kawasan Tanpa Rokok (2).

Berdasarkan data Riset Kesehatan Dasar (2013), jumlah perokok setiap hari di Sulawesi Tengah tahun 2013 mencapai 26,2\%. Data lainnya diperoleh dari data Perilaku Hidup Bersih dan Sehat (PHBS) yang dikeluarkan oleh Dinas Kesehatan Kota Palu (2013), tercatat sebanyak 43.054 atau 62,14\% kepala keluarga di Kota Palu merupakan perokok aktif (3). Penetapan Kawasan Tanpa Rokok merupakan upaya perlindungan untuk masyarakat terhadap risiko ancaman gangguan kesehatan karena lingkungan tercemar asap rokok. Penetapan Kawasan Tanpa Rokok ini perlu diselenggarakan di fasilitas pelayanan kesehatan, tempat proses belajar mengajar, tempat anak bermain, tempat ibadah, angkutan umum, tempat kerja, tempat umum dan tempat lain yang ditetapkan, untuk melindungi masyarakat yang ada dari asap rokok (4). Rumah Sakit Umum Daerah (RSUD) UNDATA Palu merupakan salah satu fasilitas pelayanan kesehatan yang seharusnya sudah $100 \%$ menerapkan kawasan tanpa rokok, tapi pada kenyataannya sampai dengan saat ini masih terdapat pengunjung yang melakukan aktifitas merokok di koridor bahkan dalam ruangan rumah sakit. Hal ini menunjukkan bahwa tidak adanya kepatuhan terhadap peraturan yang telah di tetapkan oleh pemerintah, padahal berdasarkan Perda Kota Palu Nomor 3 Tahun 2015 tentang kawasan bebas rokok, bahwa tidak di perbolehkan melakukan aktifitas merokok pada wilayah yang sudah di tetapkan sebagai Kawasan Tanpa Rokok termasuk di fasilitas pelayanan kesehatan.

Selain itu implementasi kawasan tanpa rokok di RSUD UNDATA masih terdapat hambatan atau kendala, dimana kurangnya pengawasan yang dilakukan oleh satgas KTR terhadap perokok di wilayah rumah sakit dan pemberian sanksi yang hanya berupa teguran. Larangan merokok di sekitar rumah sakit hanya berupa tempelan stiker yang hanya dipasang di beberapa dinding rumah sakit.

\section{METODE}

Jenis penelitian yang dilakukan menggunakan metode kualitatif dengan menggunakan pendekatan studi kasus. Penelitian ini dilakukan pada bulan oktober - desember 2017. Penentuan informan dilakukan melalui teknik purposive sampling dan pengumpulan data dengan teknik in depth interview. Adapun informan dalam penelitian ini adalah direktur RSUD UNDATA sebagai informan kunci, petugas pengawas kawasan tanpa rokok sebagai informan biasa, serta pengunjung RSUD UNDATA Palu sebagai informan tambahan dan pegawai di RSUD UNDATA Palu sebagai informan tambahan.

\section{HASIL DAN PEMBAHASAN}

\section{Hasil}

Konsep Komunikasi dalam Implementasi Peraturan Daerah Kota Palu Nomor 3 Tahun 2015 tentang Kawasan Bebas Rokok.

Hasil penelitian mengemukakan bahwa proses penyebaran informasi terkait kawasan tanpa rokok di RSUD UNDATA Palu melalu media cetak dan elektronik berupa pamvlet, stiker dan iklan. Informasi yang ada di media cetak dan elektronik sudah sesuai dangan yang ada di peraturan daerah kota palu nomor 3 tahun 2015 tentang kawasan bebas rokok.

\section{Konsep Konsep Sumber Daya Dalam Implementasi Peraturan Daerah Kota Palu Nomor 3 Tahun 2015 tentang Kawasan Bebas Rokok}

Hasil penelitian menjelaskan bahwa sumber daya yang ada sesuai dengan yang tertulis di SK dan tidak ada penambahan akan tetapi ada beberapa satgas yang ditarik dan dipindah tugaskan sehingga komposisi satgas yang di SK kan tidak sama seperti pertama kali di bentuk, sedangkan bentuk informasi yang di dapatkan oleh satgas kawasan tanpa rokok didapatkan langsung dari atasan dan pelatihan

\section{Konsep Konsep Disposisi dalam Implementasi Peraturan Daerah Kota Palu Nomor 3 Tahun 2015 tentang Kawasan Bebas Rokok}

Hasil penelitian mengemukakan bahwa tidak ada kriteria khusus yang diperlukan dalam pengangkatan birokrasi. Pimpinan RSUD UNDATA dan Dinas Kesehatan Provinsi Sulawesi Tengah melakukan penunjukkan kepada staf yang akan menjadi

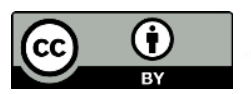


koordinator satgas KTR, yang selanjutnya koordinator akan memilih anggota satgas dari KTR. Anggota satgas kawasan tanpa rokok tidak mempunyai insentif dalam pekerjaannya kecuali gaji bulanan.

\section{Konsep Konsep Struktur Birokrasi dalam Implementasi Peraturan Daerah Kota Palu Nomor 3 Tahun 2015 tentang Kawasan Bebas Rokok}

Hasil penelitian mengemukakan bahwa koordinator satgas yang mempunyai kewenangan untuk mengatur anggotanya dan membuat jadwal jaga setiap harinya, kemudian tanggapan dari badan lain terkait implementasi kebijakan KTR di RSUD UNDATA Palu bahwa sudah baik karena anggota satgas melakukan peneguran jika mendapatkan orang yang merokok di sekitar wilayah RSUD UNDATA Palu.

\section{Pembahasan}

Konsep Komunikasi dalam Implementasi Peraturan Daerah Kota Palu Nomor 3 Tahun 2015 tentang Kawasan Bebas Rokok

Metode transmisi atau media yang digunakan dalam proses komunikasi terkait Peraturan Daerah Kota Palu Nomor 3 Tahun 2015 Tentang Kawasan Bebas Rokok ialah menggunakan metode melalui media cetak seperti pamflet, spanduk dan stiker tentang larangan merokok yang ditempel atau dipasang di beberapa titik yang mudah dilihat oleh pengunjung maupun pegawai rumah sakit. Selain media cetak, transmisi tentang Kawasan Bebas Rokok dilakukan melalui media elektronik yang berupa televisi yang ada di RSUD UNDATA Palu. Pada tayangan televisi ditampilkan isi Peraturan Daerah Nomor 3 tahun 2015, dimana pada isi peraturan tersebut membahas larangan untuk tidak merokok di berbagai tempat salah satunya adalah rumah sakit itu sendiri. Adapun konsistensitas informasi tersebut sudah konsisten dengan isi dalam Peraturan Daerah Nomor 3 Tahun 2015 Tentang Kawasan Bebas Rokok, sesuai yang telah dikatakan informan kunci maupun biasa dan bukti buku Peraturan Daerah Nomor 3 Tahun 2015 tentang Kawasan Bebas Rokok yang didapatkan oleh peneliti. Kejelasan informasi dalam proses komunikasi dalam Peraturan Daerah Nomor 3 Tahun 2015 Tentang Kawasan Bebas Rokok sudah baik. Hal ini dibuktikan dengan iklan tentang larangan merokok yang ada di televisi yang ditayangkan setiap hari. Banyaknya pamflet, baliho dan stiker yang terdapat hampir di seluruh wilayah rumah sakit. Hasil penelitian ini sesuai dengan penelitian sebelumnya (5-7).

\section{Konsep Sumber Daya dalam Implementasi Peraturan Daerah Kota Palu Nomor 3 Tahun 2015 tentang Kawasan Bebas Rokok}

Satgas Kawasan Tanpa Rokok di Rumah Sakit Umum Daerah UNDATA Palu belum memadai dari sisi jumlah, dimana hanya terdapat 15 Satgas kawasan tanpa rokok di RSUD UNDATA. Sebelumnya 5 orang satpam dan 10 orang satpol PP telah ditarik dan dipindahtugaskan ke tempat lain, sedangkan yang tertera pada surat keputusan terdapat 30 orang Satgas yang dimana terdiri dari 10 orang pegawai rumah sakit UNDATA, 10 orang satpam rumah sakit UNDATA dan 10 orang satpol PP. Satgas memperoleh informasi tentang bentuk informasi kawasan tanpa rokok dan tugas pokok sebagai Satgas kawasan tanpa rokok, informasi tersebut didapatkan dari atasan saat pembetukan Satgas kawasan tanpa rokok di RSUD UNDATA Palu, dalam hal ini informan kunci selaku koordinator Satgas, dan informan kunci telah mengikuti pelatihan sebelumnya. Hasil penelitian ini sesuai dengan penelitian sebelumnya $(8,9)$.

\section{Konsep Disposisi dalam Implementasi Peraturan Daerah Kota Palu Nomor 3 Tahun 2015 tentang Kawasan Bebas Rokok}

Proses pengangkatan birokrasi terkait Implementasi Peraturan Daerah Kota Palu Nomor 3 Tahun 2015 Tentang Kawasan Bebas Rokok melalui Koordinator Satgas kawasan tanpa rokok ialah yang ditunjuk langsung oleh pimpinan rumah sakit, yang selanjutnya koordinator akan memilih anggota Satgas dari staf yang berada di lingkungan rumah sakit. Satgas kawasan tanpa rokok yang ada pada RSUD UNDATA tidak mendapatkan insentif dari rumah sakit pada saat mengimplementasikan peraturan tersebut dikarenakan sudah menjadi tugas dari pada Satgas itu sendiri, hanya saja Satgas kawasan tanpa rokok mendapatkan gaji pokok dari negara yang mana gaji tersebut tetap didapatkan walaupun pengawas tidak melaksanakan tugasnya dengan baik. Hasil penelitian ini sesuai dengan penelitian sebelumnya (10).

\section{Konsep Struktur Birokrasi dalam Implementasi Peraturan Daerah Kota Palu Nomor 3 Tahun 2015 tentang Kawasan Bebas Rokok}

Otoritas yang paling berwenang dalam pelaksanaan implementasi kebijakan KTR di RSUD UNDATA Palu adalah koordinator Satgas yang mampu menerima dan melaksanakan kebijakan mengenai implementasi kebijakan KTR. pandangan dari badan lain terkait penerapan kawasan tanpa rokok dimana sebagian besar mendukung adanya kebijakan 
tersebut. Tetapi sebaiknya pihak rumah sakit menyediakan ruangan khusus bagi perokok. Hasil penelitian ini sesuai dengan penelitian sebelumnya (11).

\section{KESIMPULAN}

Komunikasi dalam implementasi Peraturan Daerah Kota Palu Nomor 3 Tahun 2015 tentang Kawasan Bebas Rokok sudah cukup baik. Hal ini dibuktikan dengan penyebaran informasi tentang kawasan tanpa rokok yang menggunakan beberapa media seperti media cetak dan elektronik, penyebaran informasi tentang kawasan tanpa rokok juga tersebar secara merata di kawasan Rumah Sakit Umum Daerah UNDATA Palu, para pegawai serta pengunjung rumah sakit pun sudah merasa jelas dengan informasi yang diberikan melalui media cetak dan media elektronik. Sumber daya dalam implementasi Peraturan Daerah Kota Palu Nomor 3 Tahun 2015 tentang Kawasan Bebas Rokok belum cukup baik. Hal ini dapat dilihat dari jumlah satgas yang masih kurang dan tidak sesuai dengan SK Satgas, dikarenakan Satgas yang di SK kan pada awalnya berjumlah 30 orang sedangkan yang bertugas saat ini ialah 10 orang pegawai rumah sakit dan 5 orang satpam. Disposisi atau sikap dalam implementasi Peraturan Daerah Kota Palu Nomor 3 Tahun 2015 tentang Kawasan Bebas Rokok belum cukup baik. Dapat dilihat dari mekanisme pengangkatan Satgas yang hanya dilakukan dengan penunjukan secara langsung dari koordinator. Selain itu, koordinasi yang dilakukan sangatlah minim, hal ini dapat dilihat dari agenda pertemuan Satgas yang berlangsung setahun sekali. Adapun insentif yang diberikan masih kurang yang hanya terpaku pada gaji bulanan. Struktur birokrasi dalam implementasi Peraturan Daerah Kota Palu Nomor 3 Tahun 2015 tentang Kawasan Bebas Rokok sudah cukup baik. Otoritas yang jelas dalam hal pengawasan kawasan tanpa rokok yang sudah diatur dalam Surat Keputusan Direktur RSUD UNDATA Provinsi Sulawesi Tengah, walaupun pandangan dari badan lain dalam hal ini adalah pegawai dan pengunjung rumah sakit sendiri yang menganggap peraturan tersebut sudah cukup baik.

Oleh karenanya, diharapkan Direktur Rumah Sakit Umum Daerah RSUD UNDATA Palu agar dapat memperbaiki proses pengangkatan Satgas Kawasan Tanpa Rokok di Rumah Sakit Umum Daerah RSUD UNDATA Palu, dengan cara satgas KTR yang dipilih harus memiliki beberapa kriteria yang telah ditentukan oleh Direktur Rumah Sakit Undta Palu dan siap ditugaskan sebagai satgas KTR dan bisa menyediakan tambahan insentif untuk para satgas KTR di RSUD UNDATA Palu.

\section{UCAPAN TERIMA KASIH}

Terima kasih kepada Ibu dr. Reny Arniawati Lamadjido, Sp.PK, M.Kes selaku Direktur RSUD UNDATA Palu yang telah memberikan izin untuk melakukan penelitian serta kepada Bapak Satgas KTR dan seluruh karyawan dan karyawati RSUD UNDATA terima kasih banyak telah memberikan yang telah membantu dalam pelaksanaan penelitian di RSUD UNDATA Palu.

\section{DAFTAR PUSTAKA}

1. Nururrahmah. Pengaruh Rokok Terhadap Kesehatan Dan Pembentukan Karakter Manusia. 2014;1:77-84.

2. Zulaeha. Implementasi Kebijakan Pemerintah Tentang Penetapan Kawasan Tanpa Rokok, Studi Pada Rumah Sakit Umum Daerah UNDATA Provinsi Sulawesi Tengah. Katalogis. 2015;3:58-67.

3. Riset Kesehatan Dasar. Data Perokok dan PHBS Provinsi Sulawesi Tengah Tahun 2013. 2013.

4. Kementerian Kesehatan RI. Pedoman Pengembangan Kawasan Tanpa Rokok, Kementerian Kesehatan RI Pusat Promosi Kesehatan. 2011.

5. Kartika D. Implementasi Peraturan Walikota Nomor 36 Tahun 2013 Tentang Kebijakan Kota Layak Anak. Ilmu Pemerintah. 2014;1(463):1- 13 .

6. Arianto, A., Zauhar, S. \& Hanafi I. Faktor-faktor yang Mempengaruhi Implementasi Pengembangan Budaya Kerja di Sektariat Daerah Kabupaten Pati 2015:591):201-17

7. Satrio G. Pengaruh Pemberian Pamflet Terhadap Tingkat Pengetahuan Ibu Hamil Mengenai Inisiasi Menyusui Dini. Media Med Muda. 2012;2(1):203-213.

8. Satrio G. Pengaruh Pemberian Pamflet Terhadap Tingkat Pengetahuan Ibu Hamil Mengenai Inisiasi Menyusui Dini. Media Med Muda. 2012;2(1):203-213.

9. Ratri D.K. Implementasi Peraturan Walikota Nomor 36 Tahun 2013 tentang Kebijakan Kota Layak Anak. Ilmu Pemerintah. 2014;1(463):1- 13

10. Hasan A. Implementasi Program Kartu Tanda Penduduk Elektronik Di Kecamatan Putussibau Selatan Kabupaten Kapuas Hulu. Adm Publik dan Birokrasi. 2014;1(1). 
An Idea Health Journal

11. Husna D. Peran Otoritas Jasa Keuangan (SATGAS) Dalam Perlindungan Hukum Bagi Investor Atas Dugaan Investasi Fiktif. Law Reform. 2015;11(2):207-15 